\title{
AUTHENTICATION OF UNUSED MEDICINE DONATION FOR NGOS
}

\author{
J.Esther Jenslin ${ }^{2}$ and P.Sahaya Jenitha ${ }^{2}$ S.Sri Selva Meenakshi ${ }^{3}$ \\ ${ }^{1}$ Department of Computer Application, Francis Xavier Engineering \\ College \\ ${ }^{2}$ AP Department of Computer Application, Francis Xavier Engineering \\ College \\ ${ }^{3}$ Department of Computer Application, Francis Xavier Engineering \\ College
}

\begin{abstract}
This project aims to donate medicines which are unused. The unused medicine can be donated for further utilization by a needy person. This application helps the user to donate unused medicines to NGO. Admin will login and manage members by deleting and blocking the users providing improper or expired medicines. Admin has to verify the uploaded image for their expiry date.NGO manages the stock which helps to maintain a record of the available medicine. Members can also check their previous data of medicine transactions. The donation of unused medicines is not accepted worldwide, although it is legal in some countries. A constant increase in the rate of prescription writing has prompted several charity organizations to collect a growing number of unused medicines. WHO guidelines for drug donations discourage donation of unused medicines, as this may create a number of problems. Detrimental effects of drug donations for use in emergency situations have been reported, as the arrival of unsorted, useless and expired medicines requires management and sorting, which may take up the time of health workers and eventually lead to the appearance of these drugs on the black market. However, cases of regulated donations have been reported in the USA, where several states have adopted laws in order to facilitate the redistribution of unused drugs to indigent and uninsured patients. This project aims to donate medicines which are unused. The unused medicine can be donated for further utilization by a needy person. This application helps the user to donate unused medicines to NGO. Admin will login and manage members by deleting and blocking the users providing improper or expired medicines. Admin has to verify the uploaded image for their expiry date.NGO manages the stock which helps to maintain a record of the available medicine.Members can also check their previous data of medicine transactions.
\end{abstract}

\section{KEYWORDS}

Web portal,Medicines, Medicine Donation

\section{INTRODUCTION}

This project aims to donate medicines which are unused. The unused medicine can be donated for further utilization by a needy person. This application helps the user to donate unused medicines to NGO. Admin will login and manage members by deleting and blocking the users providing improper or expired medicines. Admin has to verify the uploaded image for their 
expiry date.NGO manages the stock which helps to maintain a record of the available medicine. Members can also check their previous data of medicine transactions. The donation of unused medicines is not accepted worldwide, although it is legal in some countries. A constant increase in the rate of prescription writing has prompted several charity organizations to collect a growing number of unused medicines. WHO guidelines for drug donations discourage donation of unused medicines, as this may create a number of problems. Detrimental effects of drug donations for use in emergency situations have been reported, as the arrival of unsorted, useless and expired medicines requires management and sorting, which may take up the time of health workers and eventually lead to the appearance of these drugs on the black market. However, cases of regulated donations have been reported in the USA, where several states have adopted laws in order to facilitate the redistribution of unused drugs to indigent and uninsured patients.

Elementary education besides being a basic human need is vital for raising the standard of life, providing gainful employment, removal of regional backwardness, thereby ensuring overall development and wellbeing of a country. It is therefore the need of the hour to review the literature carried out by different academicians, educational thinkers, researchers, policymakers and educational reformers in the field of education.

\section{A Webportal for Medicine Distribution among Poverty-stricken People}

The GiveMed is a platform for the donors who want to donate their unused medicines to the poor or low-income people who need those medicines. This system will contribute to reduce the cost for national health services by making the proper use of unused medicines; and to help the poor or low-income people to get better health services.

\section{Android Application For Medicine Donation}

This medicine donation app is about the collection of medicine which is unused by the patient who recovers completely and remaining medicines becomes waste, those medicine can be collected and used further. This remaining medicines can be used by NGO's Hospitals who are indeed for those medicines. By use of this application there will be less wastage of medicines.

\section{Improvements for international medicine donations}

The World Health Organization (WHO) has developed the interagency Guidelines for Medicine Donations for use by donors and recipients in the context of emergency aid and international development assistance. Although comprehensive in nature and transferable to various emergency situations, adjustments to both content and formatting would improve this resource.

Medical donations are not always free: an assessment of compliance of medicine and medical device donations with World Health Organization guidelines (2009-2017)

Medicine and medical device donations have the potential to improve access to healthcare in some of the poorest parts of the world, but can do more harm than good. World Health Organization guidelines advise donors on how to make effective and useful donations. Our objective was to assess compliance of recent medicine or medical device donations with WHO guidelines from 2009 onwards. We searched media, academic and gray literature, including industry and organizational documents, to identify reports describing specific incidences of the donation of medicines or devices. We collected data on donation characteristics and guideline compliance. We identified 88 reports describing 53 donations. Most did not comply with at least some items in WHO guidelines and no reports provided sufficient information to assess 
compliance against all items. Donations that fail to comply with guidelines may be excessive, expired and/or burden recipient countries with storage and disposal costs. It was estimated that $40-70 \%$ of donated medical devices are not used as they are not functional, appropriate, or staff lack training. More effective donations involved needs assessments, training and the use of existing distribution networks. The donation of medicines and medical devices is frequently inadequately reported and at times inappropriate. Guidelines need to be enforced to ensure effective donations.

\section{Problem Statement}

Existing System:

1) Loss of man power

2) Cost of the medicines is high

3) It difficult to find the needy people

4) Difficult to find the donors

\section{Proposed System:}

1) It helps poor people for medicines.

2) It will help to maintain records of medicines

3) Many needy people will get cured.

4) Admin will verify the expire date

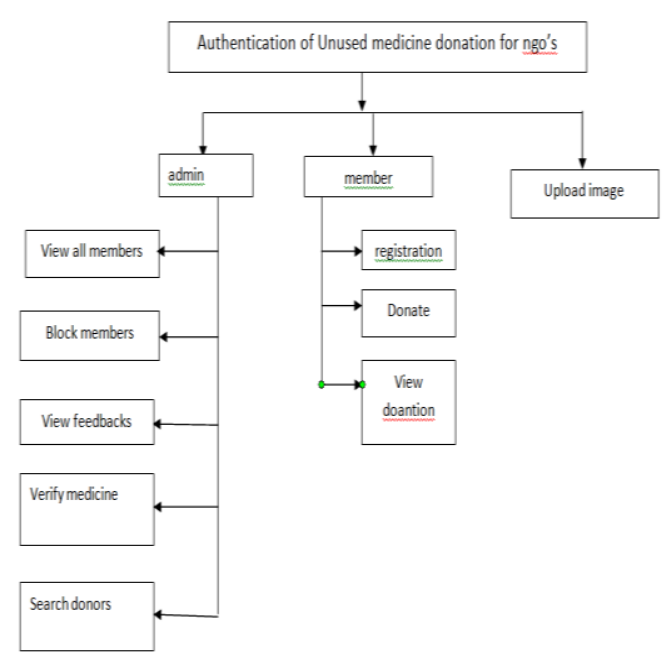

Figure :1 Architecture Diagram

\section{EXPERIMENTS AND RESULTS}

\section{Modules}

Main modules are:

$>$ Admin

$>$ User

$>$ verification for medicines 


\section{Admin:}

The admin able to add to users and also view to the all users and view the medicines.

The sub modules are:

- Verify medicine

- View users

- Block users

- Search donors

\section{User:}

The user able to donate the medicine and also view their donated.

The sub modules are:

- Donate medicine

- My donation

- Search donors

- Upload image

\section{Verification for medicine}

The admin will verify the medicine is to be expired or not.If expired the medicine is discarded

\section{Data Connection}

A database in Microsoft SQL Server consists of a collection of tables that contain data, and other objects, such as views, indexes, stored procedures, and triggers, defined to support activities performed with the data.

The data stored in a database is usually related to a particular subject or process, such as inventory information for a manufacturing warehouse.

SQL Server can support many databases, and each database can store either interrelated data or data unrelated to that in the other databases. For example, a server can have one database that stores personnel data and another that stores product-related data. Alternatively, one database can store current customer order data, and another; related database can store historical customer orders that are used for yearly reporting. Before you create a database, it is important to understand the parts of a database and how to design these parts to ensure that the database performs well after it is implemented.

\section{Output Screen}

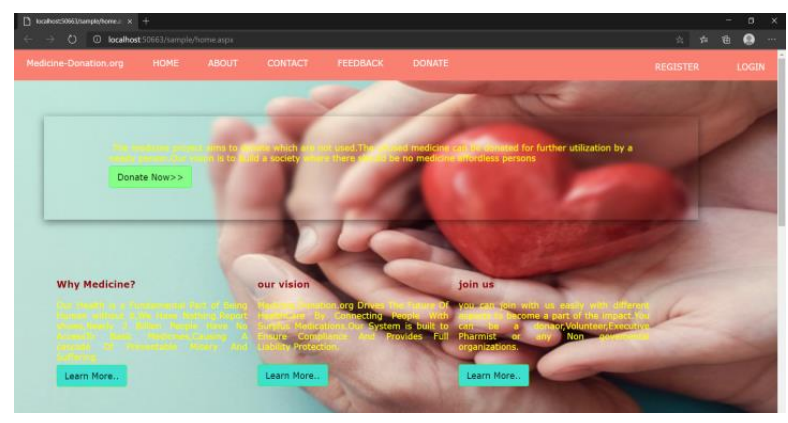

Figure : 2 


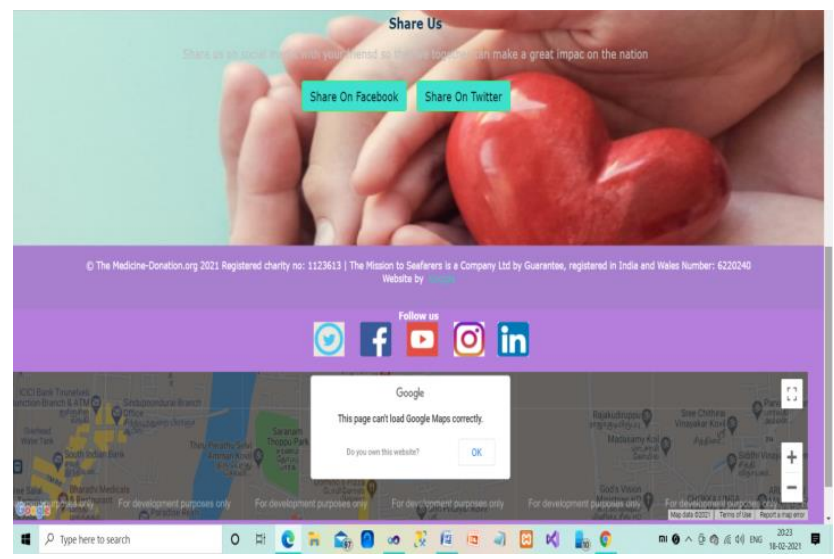

Figure :3 Home Page

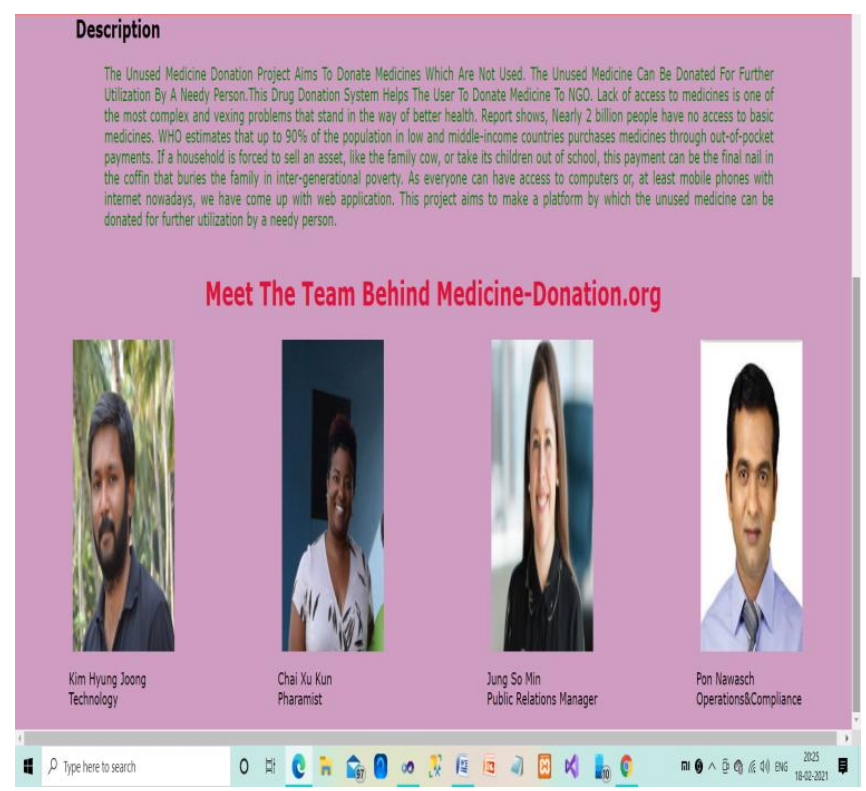

Figure: 4 About

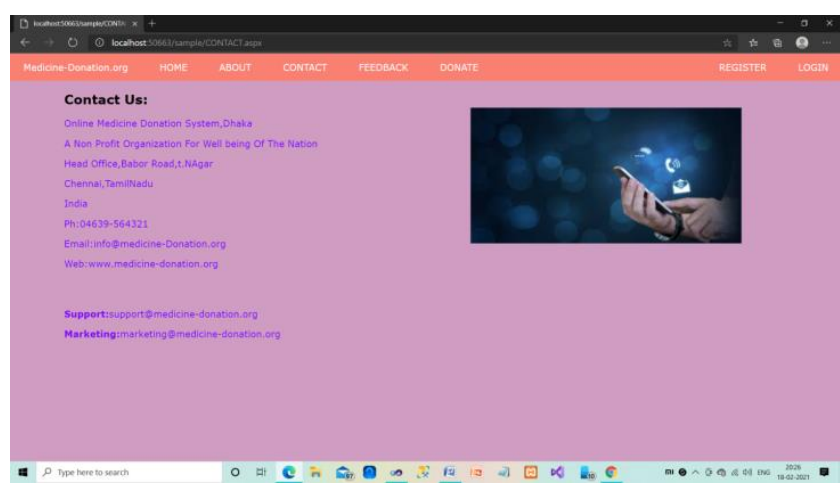

Figure :5 Feedback 


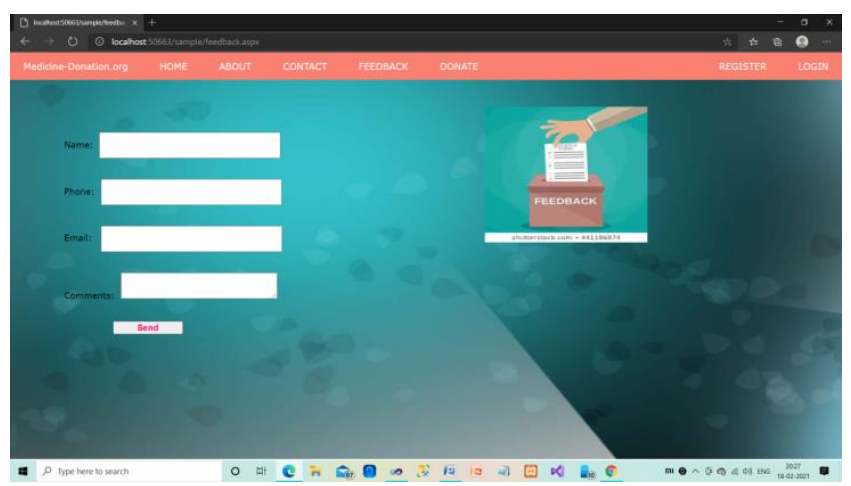

Figure :6 Feedback

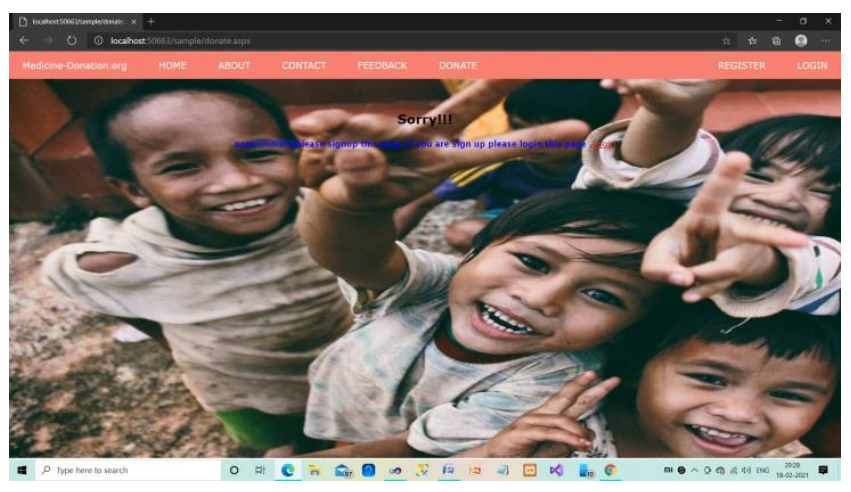

Figure :7 Donate

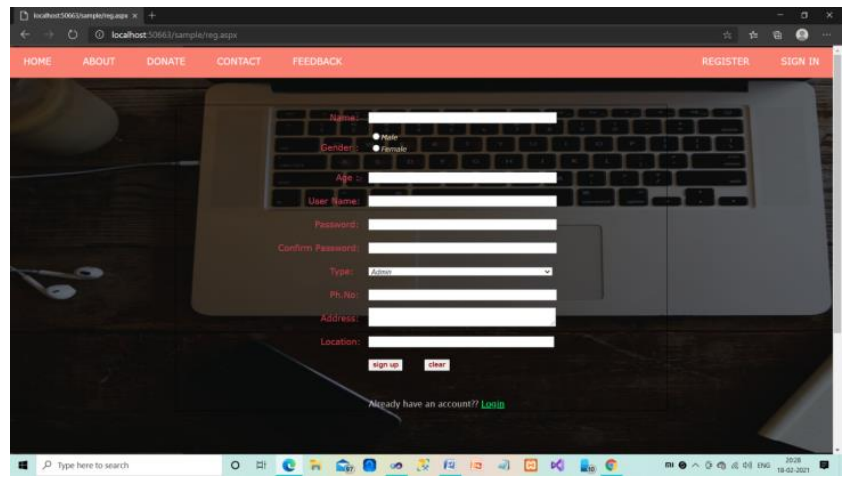

Figure :8 Registration 


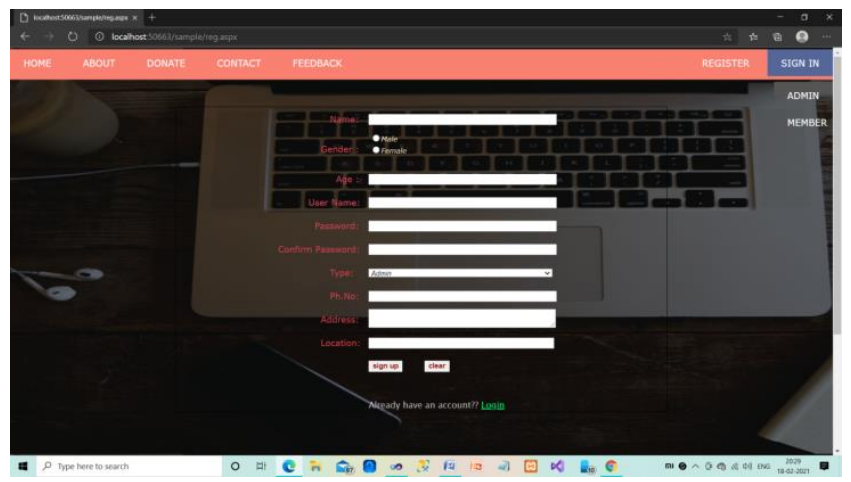

Figure :9 Sign in

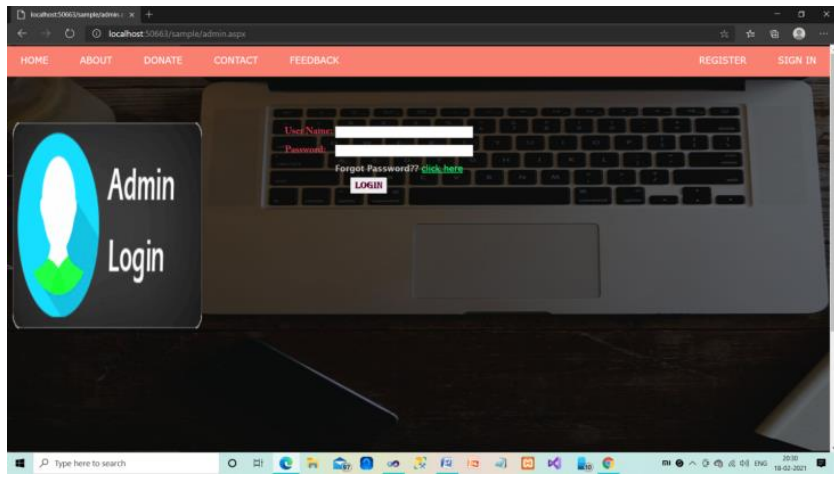

Figure :10 Admin Login Page

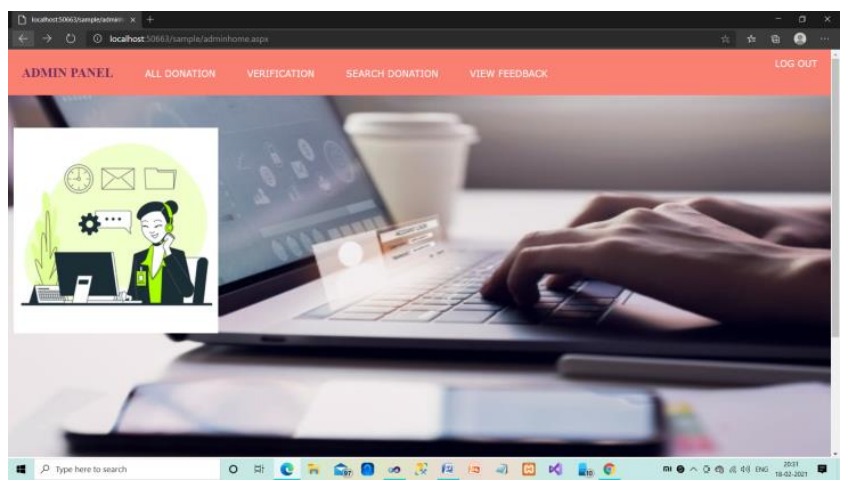

Figure :11 Sample admin main page 


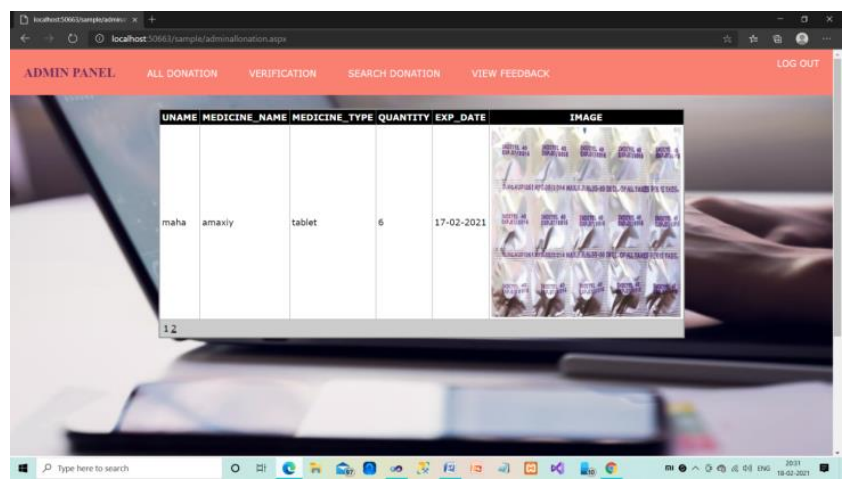

Figure :12 Donation view for admin page

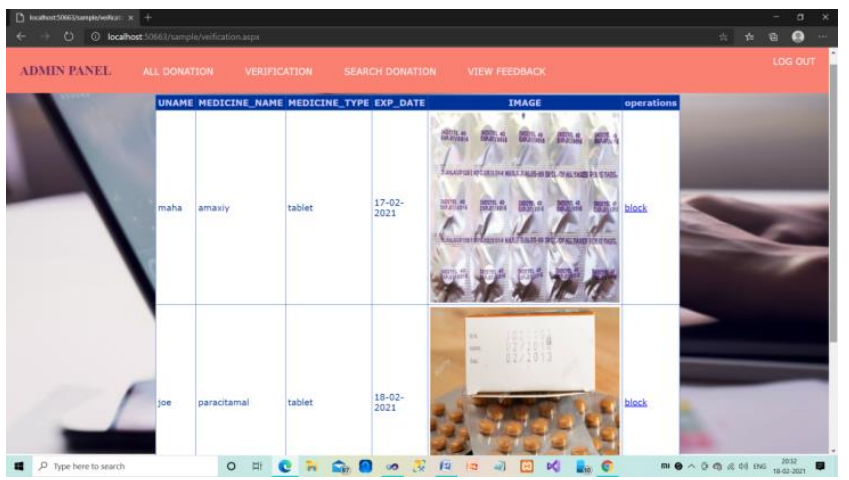

Figure : 13 Verification

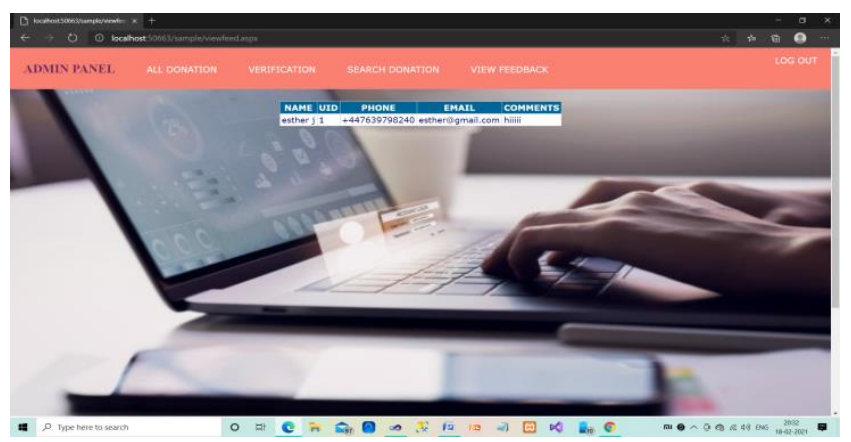

Figure :14 Feedback 


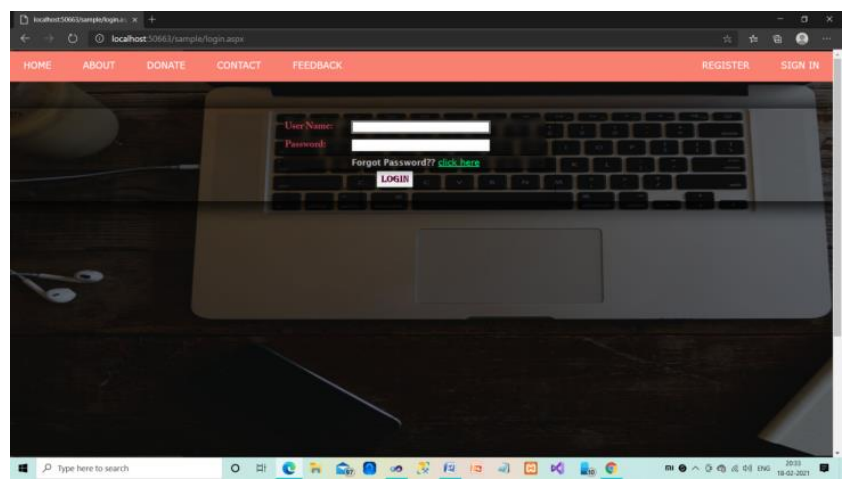

Figure : 15 User Login Page

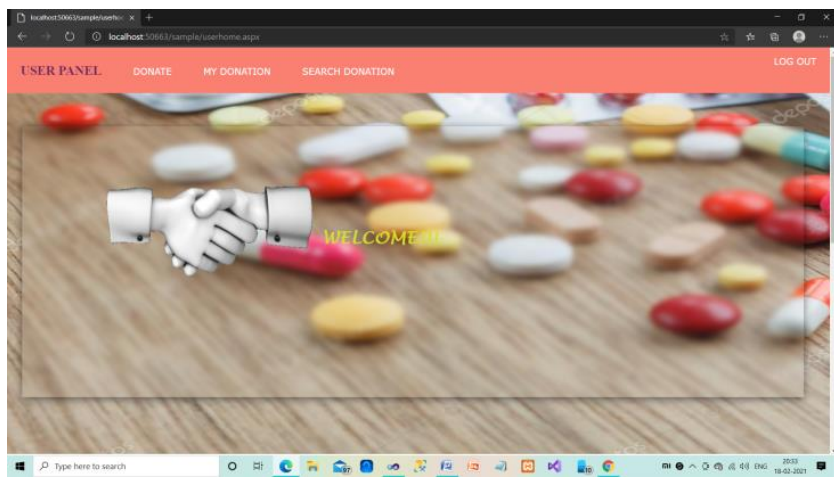

Figure :16 User Main Page

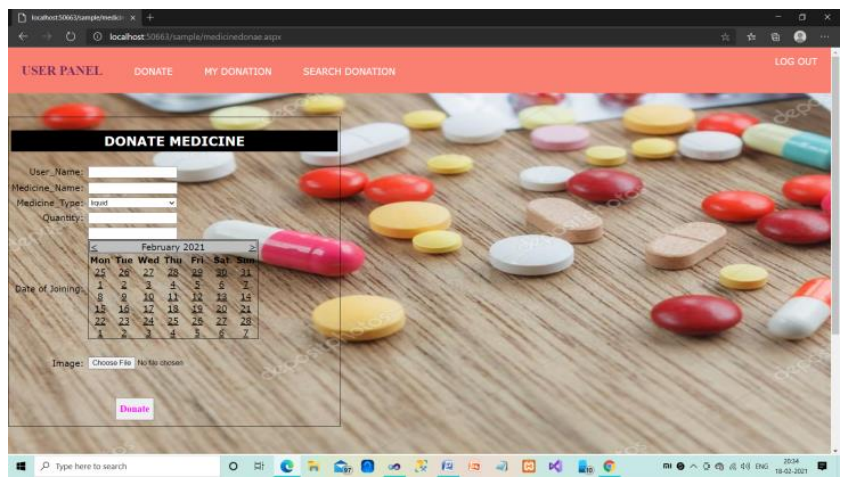

Figure :17 Donate medicine form

\section{PERFORMANCE ANALYSIS}

The existing and proposed system are analysed. The problems can be easily rectified with this concept. Nearly $70 \%$ of the performance has been increased.

\section{CONCLUSION}

This was our project of System Design about "Authentication of Unused Medicine Donation for NGOs" developed as web application based on Asp .Net programming language. The Development of this system takes a lot of efforts from us. We think this system gave a lot of satisfaction to all of us. Though every task is never said to be perfect in this development field 
even more improvement may be possible in this application. We learned so many things and gained a lot of knowledge about development field.

\section{FUTURE ENHANCEMENT}

Reduce screen interactions and time taken for checkout

Collect reviews and feedback. Provide users with the ease and convenience as against the timeconsuming task of typing long feedbacks

$>$ In future tract the location for medicine collector and distributor.

$>$ Add the doctor suggestion for the disease.

$>$ Easy to find the needy person for using GPS tracker

$>$ Add the live interaction video for doctor and patient.

\section{REFERENCES}

1) Medical donations are not always free: an assessment of compliance of medicine and medical device donations with World Health Organization guidelines (2009-2017) Sally McDonald, Alice Fabbri, Lisa Parker, Jane Williams, Lisa Bero International Health, Volume 11, Issue 5, SEPTEMBER 2019, PAGES 379-402, HTTPS://DOI.ORG/10.1093/INTHEALTH/IHZ004

2) Improvements for international medicine donations: a review of the World Health Organization Guidelines for Medicine Donations, 3rd editionNuria Cañigueral-Vila, Jennifer C. Chen, Lindsey Frenkel-Rorden, and Richard Laing

3) ANDROID APPLICATION FOR MEDICINE DONATION Netra Shigwan1, Pratiksha Chaudhari2, Shweta Pawar3, Prof Anuja Gote4 1.2,3 Student, Information Technology, Vidyalankar Institute of Technology, Wadala, Mumbai, India 4Assistant Professor, Information Technology, Vidyalankar Institute of Technology, Wadala, Mumbai, India

4) GiveMed: A Webportal for Medicine Distribution among Poverty-stricken People December 2017 DOI: 10.1109/R10-HTC.2017.8288960 Conference: Humanitarian Technology Conference (R10HTC), 2017 IEEE Region 10 Project: Development and Evaluation of Health Information Systems

5) Personalized Medicine: The Future of Health Care December 2016 The Indonesian Biomedical Journal 8(3) DOI: 10.18585/inabj.v8i3.271

6) http://www.asp.net

7) https://ieeexplore.ieee.org/document/7041139/ 


\section{Authors}

Ms.Esther Jenslin doing final year MCA in Francis Xavier Engineering College

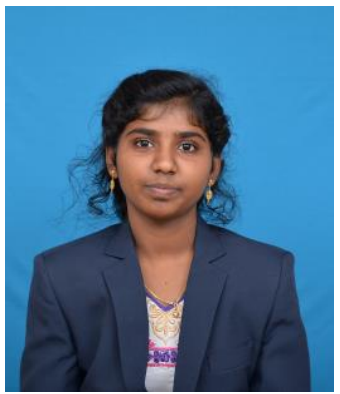

Mrs. S. Sahaya Jenitha working as Assistant Professor in the Department of Computer Applications, Francis Xavier Engineering College. Her area of interest is Wireless Sensor networks

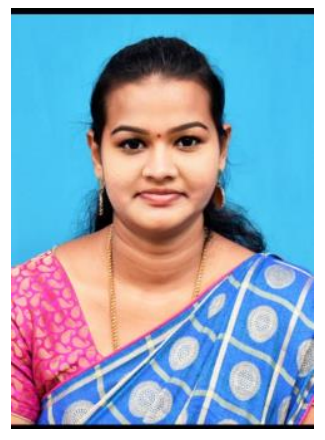

S.Sri Selva Meenakshi doing first year MCA in Francis Xavier Engineering College

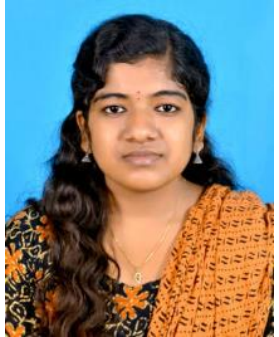

